\title{
A Comprehensive Multi-Level Approach for Passing Safe Routes to School and Complete Streets Policies in Hawaii
}

\author{
Katie M. Heinrich, Nancee N. Aki, Heidi Hansen-Smith, Mark Fenton, and Jay Maddock
}

Background: Policy changes were needed to reshape the built environment for active transportation. Methods: Using the social ecological model as a framework, the Healthy Hawaii Initiative worked with a contractor to develop a series of meetings, planning sessions, and workshops. Activities spanned 22 months between 2007 and 2009, and involved multiple stakeholders, including educational outreach for legislators and collaborative planning sessions with advocates. Results: Ultimately, with the help of the contractor to initiate the process, Complete Streets and Safe Routes to School (SRTS) legislation were introduced January 2009. Advocacy groups monitored bill progress, testified at hearings, and assisted in rewording the bills. The SRTS statute required the Department of Transportation (DOT) to administer the federal SRTS funds and the complete streets law tasked the state and county DOTs to adopt complete streets policies and review existing highway design standards and guidelines. Both bills were signed into law June 2009. Conclusions: Focusing efforts at multiple levels of the social ecological model involving champions and key stakeholders led to the successful passage of legislation supporting active transportation. Tracking policy implementation and evaluation over time will help determine actual impact on active transportation behaviors across Hawaii.

Keywords: social-ecological model, elected officials, physical activity, legislation

Over the past 20 years, leisure-time physical activity rates have stabilized, while rates of obesity have climbed. ${ }^{1-3}$ Decreases in non-leisure-time physical activity such as active commuting may be contributing to the obesity epidemic. ${ }^{4}$

Interventions to increase physical activity through individual and social approaches have shown modest effects. $^{5}$ The social ecological model postulates that behavior is influenced by a variety of factors including not only individual level knowledge, attitudes, and behaviors but also policy, institutional, community, and societal level influences. ${ }^{6}$ Accordingly, community and policy-level interventions should have the greatest population reach and may be the most effective for widespread behavior change. ${ }^{6}$

Nationwide, 2 policies have been gaining support to improve the safety of pedestrians and cyclists for active transportation: Safe Routes to School (SRTS) and Complete Streets. SRTS is a comprehensive approach to increase walking and biking to school through engineering, education, enforcement, encouragement and evaluation. ${ }^{7}$ Complete streets focus on safely accommodating

Heinrich is with the Dept of Kinesiology, Kansas State University, Manhattan, KS. Aki and Hansen-Smith are with the Healthy Hawaii Initiative, Hawaii State Dept of Health, Honolulu, HI. Fenton is with Fenton Consulting, Boston, MA. Maddock is with the Dept of Public Health Sciences, University of Hawaii, Honolulu, HI. all modes of transportation, prioritizing pedestrians and cyclists, through a variety of policies and practices. ${ }^{8}$ While both SRTS and complete streets include a variety of activities, statewide enabling legislation is often essential to ensure broad changes at the highest level of the social ecological model.

Public health professionals and advocates cannot enact policy directly. To have an impact, multisectoral partnerships are essential to influence key decision-makers who enact policies and procedures. ${ }^{9,10}$ This manuscript summarizes the process and lessons learned from passing SRTS and complete streets legislation at the state level using the framework of the social ecological model.

\section{Methods}

The Healthy Hawaii Initiative (HHI) was established in 2000 to lead statewide chronic disease prevention efforts for the Hawaii State Department of Health (DOH). ${ }^{11} \mathrm{HHI}$ initially began to focus on improving the built environment for active transportation to address high rates of pedestrian $^{12}$ and bicyclist ${ }^{13}$ fatalities and lack of prioritization of these issues by policy-makers in Hawaii. ${ }^{14}$

For statewide policy change, HHI formulated a multilevel approach based on the social ecological model (Figure 1) ${ }^{6}$ to be delivered through a series of meetings, training sessions, and workshops with diverse stakeholders. HHI contracted with an expert consultant (Mark Fenton) who had a multidisciplinary background 
in physical activity, health, planning, and engineering. All efforts targeted involvement of influential champions (eg, Lieutenant [Lt.] Governor, Director of Health) as well as key stakeholders (eg, legislators, planners, advocates), and focused on capacity building through multidisciplinary partnerships. It was important to build multisectoral support along with capacity for policy enactment by the appropriate city, county, and statelevel officials.

Table 1 displays a chronological list of activities, spanning 22 months (September 2007-June 2009). Unless specifically indicated, all activities took place in Honolulu County, were hosted by HHI and were facilitated by Mark Fenton.

Evaluation was incorporated from the beginning, coordinated by the Office of Public Health Studies at the University of Hawaii. Evaluation tools were individually designed for each activity querying understanding, information learned, presentation effectiveness and relevance, and suggestions for next steps.

\section{Results}

\section{Community Members}

Community members were invited to "Active Living Community Workshops" in Honolulu and Maui Counties. Despite various promotion strategies for the 3 Honolulu workshops (eg, flyers, newspaper advertisements), there were only 18 attendees. Redesigned recruitment strategies for the 6 Maui workshops targeted professionals, and included newsletter and local radio announcements, posters, letters, and individual phone calls by local coalition members, resulting in 58 attendees. Evaluation results indicated increased knowledge of the presented concepts for $>50 \%$ of participants.

\section{Advocacy Groups}

Strategic planning sessions were held with community advocacy groups in August 2008. It is important to note that several organizations had already formed a coalition

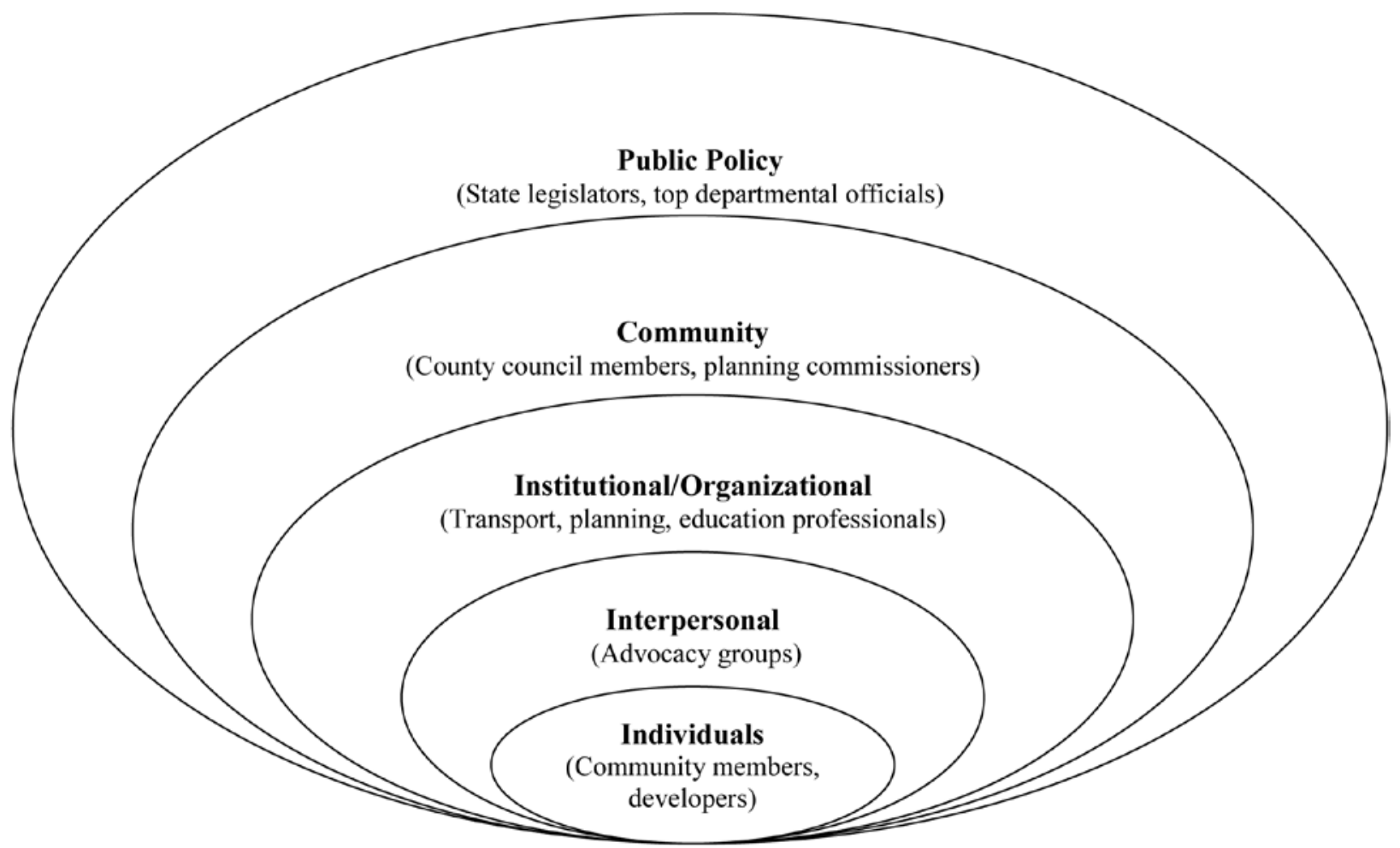

Figure 1 - Social Ecological Model framework, with examples of target audiences. The model posits that it is not sufficient to simply educate and encourage individuals for behavior change at the population level (eg, community workshops with residents). Rather, it is more effective to make changes from the top down, where policy changes can have the broadest impact. By focusing on multiple levels, simultaneous changes can lead to system-wide changes. Advocacy groups were targeted due to the larger scale social marketing and interpersonal engagement they provided; transportation, planning, and public health professionals were provided technical training so their institutions (government departments) could embrace change; policy makers were targeted to support environmental improvements (eg, traffic calming near schools); and state legislators and department heads were targeted to support state-level legislation to enable further progress at all levels. 
Table 1 Chronological List of Healthy Hawaii Initiative Activities That Led to Safe Routes to School and Complete Streets Policy Changes

\begin{tabular}{|c|c|c|c|}
\hline Date & Activity (number) & Theme & Attendees (number) \\
\hline August 2007 & Workshop & $\begin{array}{l}\text { Earning Healthier Profits } \\
\text { with Healthy Designs }\end{array}$ & $\begin{array}{l}\text { Planners, Developers, Lt. Governor, State } \\
\text { Director of Health (38) }\end{array}$ \\
\hline Throughout 2008 & One-on-one Meetings & $\begin{array}{l}\text { Education about active living } \\
\text { communities and updates about } \\
\text { planned activities }\end{array}$ & $\begin{array}{l}\text { Representatives from departments of } \\
\text { permitting and planning, county council } \\
\text { members and county commissioners }(6)\end{array}$ \\
\hline March 2008 & Informational Meetings & Invitations to community workshops & $\begin{array}{l}\text { State Representative, State Senator, City } \\
\text { Councilmember (5) }\end{array}$ \\
\hline March 2008 & $\begin{array}{l}\text { Leeward Oahu Community } \\
\text { Workshops ( } 3 \text { ) }\end{array}$ & Active Living Communities & $\begin{array}{l}\text { Community residents, parents, state } \\
\text { employees, advocates, students (18) }\end{array}$ \\
\hline July 2008 & Survey of Planners and Developers & The Built Environment and Health & $\begin{array}{l}\text { Planners, developers, architects, } \\
\text { and landscapers (5) }\end{array}$ \\
\hline \multirow[t]{5}{*}{ August 2008} & $\begin{array}{l}\text { Strategic Planning Sessions } \\
\text { ( } 5 \text { organizational sessions; } 1 \text { joint } \\
\text { session) }\end{array}$ & Active Living Communities & $\begin{array}{l}\text { State Nutrition and Physical Activity } \\
\text { Coalition and Department of Education } \\
\text { representatives (33) }\end{array}$ \\
\hline & & & Honolulu YMCA (24) \\
\hline & & & Hawaii Bicycling League (4) \\
\hline & & & AARP \& One Voice for Livable Islands (38) \\
\hline & & & Joint collaborative session (16) \\
\hline December 2008 & Planning Session & $\begin{array}{l}\text { Achieving Complete Streets through } \\
\text { Safe Routes to School, Part II }\end{array}$ & $\begin{array}{l}\text { Community advocacy organizations (Hawaii } \\
\text { NPAC, HBL, PATH, One Voice, Sierra } \\
\text { Club, Kailua Urban Design Task Force), } \\
\text { government agencies (Hawaii State Depart- } \\
\text { ments of Health and Transportation, City } \\
\text { and County of Honolulu Departments of } \\
\text { Transportation Services, Planning and Per- } \\
\text { mitting, and Police, and Hawaii, Kauai, and } \\
\text { Maui Counties Planning Departments; 22) }\end{array}$ \\
\hline December 2008 & Policy-maker's breakfast & $\begin{array}{l}\text { Creating more Livable, Activity, } \\
\text { Healthy Communities }\end{array}$ & $\begin{array}{l}\text { Elected officials from the Hawaii State } \\
\text { Legislature, County Councils, appointed } \\
\text { officials (16) }\end{array}$ \\
\hline \multirow[t]{2}{*}{ January 2009} & Policies Introduced & $\begin{array}{l}\text { Schools; Traffic Safety; Relating } \\
\text { to Education (House Bill No. 983) }\end{array}$ & \\
\hline & & $\begin{array}{l}\text { Complete Streets; Roads and High- } \\
\text { ways; Relating to Transportation } \\
\text { (Senate Bill No. 718) }\end{array}$ & \\
\hline June 2009 & Policies Signed into Law & $\begin{array}{l}\text { Act } 54 \text { (SRTS) \& Act } 100 \\
\text { (complete streets) }\end{array}$ & \\
\hline
\end{tabular}


called One Voice, with the goal of passing complete streets legislation. One Voice was included in these sessions. The consultant met with each group separately for skill building, knowledge development, and action planning, followed by a joint session. Over $90 \%$ indicated improved knowledge of active transportation information and design strategies. In the joint session, advocacy groups prioritized shared goals with SRTS and complete streets as key policy issues; however key stakeholders, especially the Department of Transportation (DOT) and the state SRTS coordinator, were missing.

\section{Planners and Developers}

Key planners and developers $(\mathrm{n}=38)$ attended an August 2007 workshop, "Earning Healthier Profits with Healthy Designs." The Lt. Governor and Director of Health spoke about the importance of active transportation and pedestrian and bicyclist safety. Discussion topics included zoning, density, parking, permitting, and education. Over half $(61.5 \%)$ improved their understanding of the built environment and physical activity, $50 \%$ learned strategies for improving the built environment to promote physical activity, and $58.3 \%$ felt these issues were extremely important to their work. However, participants indicated that current ordinances and standards were prohibitive.

A July 2008 planner and developer survey queried issues and suggestions for healthy design. Though a small sample (3 planners, 2 developers), respondents were key stakeholders with opinions valued by their peers. Suggestions included improving zoning codes and standards, increasing government leadership and knowledge, improving pedestrian friendliness, allowing for mixed use development, policy changes (including complete streets), code changes to increase walkability, adding bicycle facilities, providing incentives, and expediting permits and reducing parking requirements.

\section{Advocacy Groups, Transportation Planners, Education Professionals}

A Physical Activity and Nutrition (PAN) Summit "Good Health: The Ultimate Bottom Line" was held in October 2007 to introduce active transportation and community design concepts to 302 attendees representing businesses, schools, and community agencies. Speakers included the Hawaii Governor, Lt. Governor, and the Director of Health. Evaluation results indicated that $>75 \%$ of attendees improved their knowledge of built environment concepts and strategies and $97 \%$ were provided with beneficial networking opportunities.

In October 2008, a smaller PAN Forum (98 participants with 44 who attended the 2007 PAN Summit) focused on "Good Health: Creating Active Living Communities." Key speakers included the Lt. Governor and the Director of Health. Evaluation results indicated 67\% of participants felt issues discussed were important for their work. Qualitative comments indicated the information presented and networking opportunities were helpful. Participants prioritized "change zoning policies to create a more walkable and bikeable Hawaii" and "adopt complete streets legislation" as the most important policies for creating active living communities.

Following the PAN Forum, an afternoon planning session "Achieving Complete Streets through Safe Routes to School" was held $(n=33)$. Ninety percent felt that complete streets could be achieved through SRTS. Although rated as highly collaborative and informational, $30 \%$ felt the session was unsuccessful in developing a preliminary plan to achieve complete streets through SRTS or identifying next steps for their organizations in this process. Over $96 \%$ wanted to learn more about complete streets, SRTS, and the connections between them. Missing key stakeholders (although invited) included the Hawaii SRTS coordinator, State and County Planning officials, legislators, and private schools.

\section{Advocacy Groups, City, County, and State Planning, Health and Transportation Officials}

HHI recruited additional key stakeholders to a December 2008 follow-up planning session, "Achieving Complete Streets through Safe Routes to School, Planning Session, Part II." Attendees included advocates and state and county government employees from health, transportation, and planning departments $(n=22)$. This session resulted in a defined plan for achieving complete streets through SRTS. All participants rated the session as productive, collaborative, and helpful for networking. Participants rated all activities as somewhat to very helpful and were committed for continued efforts toward a statewide complete streets policy and SRTS programming. Although invited, missing key stakeholders included Department of Education representatives and the State SRTS coordinator.

\section{State Legislators and Departmental Officials}

Throughout 2008, 6 individual meetings (plus other informal conversations) were held with city and county permitting and planning representatives, county council members and county commissioners to explain and provide updates about planned activities and to engender support. In March, an informational meeting invited policy makers (ie, state representatives, state senators, and city council members) to workshops planned for their communities.

\section{State Legislators}

In December 2008, HHI convened 16 elected officials at a policymaker's breakfast to brief them on built environment activities, highlight relevant local policies, and provide national policy examples (eg, complete streets, SRTS, zoning for active living) for implementation in Hawaii. The consultant provided example language for complete streets and SRTS policies and offered his services as a resource for developing Hawaii legislation. 


\section{Policy Change}

Legislators who attended the breakfast introduced SRTS (House Bill No. 983) and complete streets (Senate Bill No. 718) legislation in January 2009. Although legislators had the final vote on statewide policies, it was important to have broad stakeholder support. Many groups supported the policies under the umbrella of One Voice. For instance, AARP (senior citizens), YMCAs (children and families), bicycle league, trail advocates, and nutrition and physical activity coalitions. These advocacy groups closely monitored the bills, testified at hearings, and helped craft amendments. By hearing all of these diverse interest groups working together for a common cause, enough legislators were convinced to vote in favor of these policies.

The SRTS statute articulated expectations for the DOT administration of SRTS funds. The complete streets law tasked the state and county DOTs with adopting complete streets policies and establishing a temporary taskforce to review existing highway design standards and guidelines (see Table 2). In June 2009, both bills were signed into law by Hawaii's Governor as Act 100 (SRTS) and Act 54 (complete streets).

\section{Conclusions}

A comprehensive multilevel social ecological approach was influential in the passage of SRTS and complete streets statewide policies in Hawaii. ${ }^{15}$ These policy changes resulted from concentrated educational, capacity building and networking efforts over a 2-year period. The approach was structured to facilitate collaboration of multiple stakeholders led by an expert consultant.

The model presented here may be useful for other states who are interested in passing similar legislation using a social ecological focus. The social ecological

\section{Table 2 Description of Legislation for Safe Routes to School (SRTS) and Complete Streets}

\begin{tabular}{|c|c|}
\hline \multicolumn{2}{|c|}{ Act 100-SRTS (House Bill No. 983) http://www.capitol.hawaii.gov/session2009/Bills/HB983_CD1_.htm } \\
\hline Description & $\begin{array}{l}\text { Requires the director of transportation to provide federal SRTS program funds for school-based workshops } \\
\text { and community-based planning projects that will reduce vehicular travel and congestion, encourage walking } \\
\text { and bicycling, and promote health and safety. Requires the director to develop a streamlined process for the } \\
\text { federal SRTS grant program. }\end{array}$ \\
\hline & $\begin{array}{l}\text { The director of transportation shall submit to the legislature a report of the status and progress of the SRTS } \\
\text { program, no later than } 20 \text { days before the convening of the regular session of } 2010 \text {. }\end{array}$ \\
\hline Purpose & $\begin{array}{l}\text { (1) Enhance traffic safety, especially around Hawaii's schools; (2) Enable and encourage children to walk and } \\
\text { bicycle to school; and (3) Make bicycling and walking to school a safer and more appealing transportation } \\
\text { alternative through the federal SRTS program. }\end{array}$ \\
\hline
\end{tabular}

Act 54-Complete Streets (Senate Bill No. 718) http://www.capitol.hawaii.gov/session2009/bills/SB718_HD1_.htm

Description Requires the department of transportation and the county transportation departments to seek to reasonably accommodate access and mobility for all users of public highways, including pedestrians, bicyclists, transit users, motorists, and persons of all abilities. Establishes a temporary task force to review certain highway design standards and guidelines. Report to legislature in 2010 and 2011.

Purpose

The department of transportation and the county transportation departments shall adopt a complete streets policy that seeks to reasonably accommodate convenient access and mobility for all users of the public highways within their respective jurisdictions as described under section 264-1, including pedestrians, bicyclists, transit users, motorists, and persons of all ages and abilities.

(b) This section shall apply to new construction, reconstruction, and maintenance of highways, roads, streets, ways, and lanes located within urban, suburban, and rural areas, if appropriate for the application of complete streets.

(c) This section shall not apply if:

(1) Use of a particular highway, road, street, way, or lane by bicyclists or pedestrians is prohibited by law, including within interstate highway corridors;

(2) The costs would be excessively disproportionate to the need or probable use of the particular highway, road, street, way, or lane;

(3) There exists a sparseness of population, or there exists other available means, or similar factors indicating an absence of a future need; or

(4) The safety of vehicular, pedestrian, or bicycle traffic may be placed at unacceptable risk." 
model was essential for moving the policy agenda forward in a collaborative way incorporating interests of multiple stakeholders. The goal of these efforts extended beyond merely introducing and passing the policies through the legislature; rather, the time and money used to facilitate the activities was spent to create broad changes in perspectives and priorities for successful policy and programmatic implementation.

Knowledge of targeted communities was also critical and was facilitated by working with coalitions, advocacy groups, and government officials in each county. Through this process we learned the best way to get multiple parties to the table was to enlist the aid of key stakeholders within the community who were both passionate about the issues at hand and trusted as leaders. We also made sure to invite the appropriate organizations or individuals to the appropriate levels or types of activities in order not to waste anyone's time. Then, each activity was structured to either result in knowledge gain, formation of collaborative partnerships or a definitive agenda of next steps. Due to the involvement of multiple stakeholders, ${ }^{15}$ it was important to value everyone's work including unique roles and resources each party could provide. For example, HHI was unable to advocate for legislation, while community advocates could do so.

Flexibility of HHI's funding allowed for a variety of workshops, meetings, and planning sessions. Other "must haves" for success were the incorporation of evaluators and a contractor from the beginning. On-going evaluation allowed HHI to learn from each activity and capitalize on timely opportunities (eg, collaborating with advocacy groups interested in complete streets and SRTS). The consultant was especially skilled at facilitating communication and cooperation between groups.

The unique opportunities to collaborate at multiple levels across sectors in such a geographically isolated state such as Hawaii may differ for other states. Sparse attendance at Honolulu community workshops illustrated challenges for a state $\mathrm{DOH}$ of eliciting change from the grassroots level. Similarly, the absence of key stakeholders at some activities indicated a need to provide a higher level of stimulus for their engagement. Although collaborators had their own agendas and priorities, it was clear that everyone recognized the unique timing for the policy advancement.

Future plans include tracking policy implementation to determine impact on active transportation. Along with the governor, many state legislators are up for reelection in 2010. Thus, HHI and advocates will educate newly elected policy-makers as necessary. ${ }^{11}$

\section{Acknowledgments}

We are very grateful to the elected officials who attended HHI activities, introduced, supported, and voted for the SRTS and complete streets legislation including Representative Joe Bertram, III, Senator Kalani English, Senator Mike Gabbard, Representative Karen Awana, Representative Marilyn Lee, and City Council Member Todd Apo. Former Hawaii County Deputy Director of Planning Brad Kurakawa, and former Hawaii County Mayor Harry Kim were instrumental in our commencement of these activities. The help and support of community advocacy groups including AARP Hawaii, Hawaii Bicycling League, One Voice for Livable Islands, People's Advocacy for Trails Hawaii, Kauai PATH, Oluwalu, and Jonathan Starr; local developers including Kimo Steinwascher-Kaneohe Ranch, Bill Frampton and Dave Ward of Olowalu Town, LLC; coalitions including Sandy McGuinness-Maui Nutrition \& Physical Activity Coalition, Bev Brody, Get Fit Kauai-NPAC ; and county government officials including the Lanai Department of Health, and Dave DeLeon and Jeff Hunt from the Maui County Department of Planning were invaluable. This project was funded by the Tobacco Settlement Special Fund, Healthy Hawaii Initiative, Hawaii State Department of Health.

\section{References}

1. Centers for Disease Control and Prevention. Trends in leisuretime physical inactivity by age, sex and race/ethnicityUnited States, 1994-2004. MMWR. 2005;54:991-994.

2. Mokdad AH, Ford ES, Bowmqan BA, et al. Prevalence of obesity, diabetes, and obesity-related health risk factors, 2001. JAMA. 2003;289:76-79.

3. Centers for Disease Control and Prevention. Behavioral Risk Factor and Surveillance System. www.cdc.gov/brfss. Accessed on-line on July 27, 2010.

4. Rodriguez D. Active transportation: making the link from transportation to physical activity and obesity. Active Living Research, Research Brief, 2009.

5. Guide to Community Preventive Services. Behavioral and social approaches to increase physical activity: individually-adapted health behavior change programs. www.thecommunityguide.org/pa/behavioral-social/individuallyadapted.html. Last updated: April 8, 2010.

6. Sallis JF, Owen N. Ecological models of health behavior. In: Glanz K, Rimer BK, Lewis FM, eds. Health education and health behavior: theory, research and practice. 3rd ed. San Francisco: Jossey-Bass; 2002:462-484.

7. National Safe Routes to School Task Force. Safe Routes to School: A Transportation Legacy. 2008. Accessed on-line at http://www.saferoutesinfo.org/task_force/collateral/ task_force_report.web.pdf on August 2, 2010.

8. Brock E. Complete Streets aim to please all users. Am City County. 2008;123(13):17-18.

9. Geraghty AB, Seifert W, Preston T, Holm CV, Duarte TH, Farrar SM. Partnership moves community toward Complete Streets. Am J Prev Med. 2009;37:S420-S427.

10. Deehr RC, Shumann A. Active Seattle: achieving walkability in diverse neighborhoods. Am J Prev Med. 2009;37(6S2):S403-S411.

11. Maddock JE. Evaluation of a statewide program to reduce chronic disease: the Healthy Hawaii Initiative, 2000-2004. Eval Program Plann. 2006;69:293-300.

12. National Highway Traffic Safety Administration. Traffic Safety Facts, 2007 data: Pedestrians. DOT HS 810994. Washington DC: NHTSA's National Center for Statistics and Analysis; 2007.

13. National Highway Traffic Safety Administration. Traffic safety facts, 2007 data: bicyclists and other cyclists. DOT HS 810 986. Washington DC: NHTSA's National Center for Statistics and Analysis; 2007.

14. Maddock JE, Reger-Nash B, Heinrich K, Leyden KM, Bias TK. Priority of activity-friendly community issues among key decision makers in Hawaii. J Phys Act Health. 2009;6(3):386-390.

15. Thomas IM, Sayers SP, Godon JL, Reilly SR. Bike, walk, and wheel: a way of life in Columbia, Missouri. Am J Prev Med. 2009;37(6, Suppl 2):S322-S328. 